\title{
OBJETO DE APRENDIZAGEM - ENSINO DE SISTEMAS DE EQUAÇÕES LINEARES APLICADOS EM CIRCUITOS
}

\author{
LEARNING OBJECT - TEACHING LINEAR EQUATION SYSTEMS APPLIED IN \\ CIRCUITS
}

\author{
Fábio Mendes Ramos ${ }^{1}$
}

\begin{abstract}
RESUMO: O presente estudo, apesar de não se tratar de assunto novo no âmbito educacional, vem a colaborar com o tema é Prática pedagógica, no Ensino de Sistemas de Equações Lineares, teve como pressuposto a elaboração de um Objeto de Aprendizagem para o Ensino Médio e Educação Profissional, o qual foi desenvolvido como método dinâmico e interativo para o ensinoaprendizagem desse conteúdo. A metodologia empregada buscou instrumentar da tecnologia informática na elaboração de um Objeto de Aprendizagem, desenvolvido e implementado em sua pluralidade nos softwares GeoGebra e Notpad++ por meio de uma sequência didática. As atividades dessa sequência foram elaboradas e aplicadas a estudantes do Ensino Médio e Educação Profissional. Espera-se que o Objeto de Aprendizagem contribua para a reflexão e melhor compreensão dos alunos, possibilitando uma relação entre os conteúdos de Matemática e das áreas técnicas na resolução de problemas de Circuito de malhas. O Objeto de Aprendizagem foi disponibilizado no site (http://www.fabioramos.mat.br/), visando a (re)utilização por professores, pesquisadores e alunos.
\end{abstract}

Palavras-chave: Objeto de Aprendizagem. Ensino de Matemática. Sistemas de Equações lineares. Circuitos de malhas.

ABSTRACT: The present study, despite not being a new subject in the educational scope, comes to collaborate with the theme is Pedagogical practice, in the Teaching of Systems of Linear Equations, it had as presupposition the elaboration of a Learning Object for the High School and Professional Education, which was developed as a dynamic and interactive method for teaching and learning this content. The methodology employed sought to instrument computer technology in the elaboration of a Learning Object, developed and implemented in its plurality in the GeoGebra and Notpad ++ software through a didactic sequence. The activities in this sequence were designed and applied to high school and professional education students. It is expected that the Learning Object will contribute to the reflection and better understanding of the students, enabling a relationship between the contents of Mathematics and the technical areas in solving loop problems. The Learning Object

\footnotetext{
I Doutorado em andamento no Programa de Pós-Graduação em Ensino de Ciências Exatas pela UNIVATES. Mestre em Ensino de Ciências e Matemática pela PUC Minas e graduação em Matemática pela UNIMONTES. Professor de Matemática do Instituto Federal de Educação, Ciências e Tecnologia do Norte de Minas Gerais - IFNMG, com experiência na docência do Ensino Básico, Técnico e Superior. Pesquisador na área de Educação Matemática, Objetos de Aprendizagem e Tecnologia no Ensino. Email: fabio.ramos@ifnmg.edu.br.
} 
was made available on the website (http://www.fabioramos.mat.br/), aiming at the (re) use by teachers, researchers and students.

Keywords: Learning Object. Mathematics teaching. Systems of linear equations. Mesh circuits.

\section{INTRODUÇÃO}

Na prática, docente é possível verificar as dificuldades de aprendizagem de muitos alunos do ensino médio e Educação Profissional em relação a determinados conteúdos das ciências exatas. Dentre essas dificuldades, estarei apresentado uma proposta de intervenção pedagógica desenvolvida no conteúdo de sistemas de equações lineares.

Atualmente, o uso dos recursos tecnológicos está presente no cotidiano de grande parte da população, inclusive dos estudantes. Estes utilizam a tecnologia de diversas maneiras e para variados fins, seja na aquisição de informação ou como lazer. Assim sendo, trazer a tecnologia informática para o interior da escola pode ser um instrumento motivador para o processo ensino-aprendizagem do educando. Sobre a habilidade dos alunos em relação aos recursos tecnológicos, Almeida (2000, p. Io8) considera que:

Os alunos por crescerem em uma sociedade permeada de recursos tecnológicos, são hábeis manipuladores da tecnologia e a dominam com maior rapidez e desenvoltura que seus professores. Mesmo os alunos pertencentes as camadas menos favorecidas têm contato com recursos tecnológicos na rua, na televisão, etc., e sua percepção sobre tais recursos é diferente da percepção de uma pessoa que cresceu numa época em que o convívio com a tecnologia era muito restrito.

O incentivo governamental e a ampliação das escolas técnicas de nível médio permitem um aumento quantitativo de profissionais atuantes nessa modalidade de ensino, entre eles, o professor de Matemática. Um dos propósitos dos cursos técnicos é que o discente tenha acesso imediato ao mercado de trabalho, capacitando-o com conhecimentos teóricos e práticos em diversas atividades do setor produtivo, muitos profissionais do ensino de Matemática encontram dificuldade em relacionar os conteúdos dessa disciplina à área técnica.

Assim, com a ampliação dos Institutos Federais e o aumento de adesões de outras instituições de ensino nos cursos de formações de educação profissional, verifica-se a necessidade de produção de materiais didáticos específicos para esse tipo de formação. Também observa-se uma maior demanda no que diz respeito à estruturação física e laboratorial nas referidas instituições, de modo a que se obtenha melhor qualidade do ensino.

Considerando que a aprendizagem torna-se potencialmente mais efetiva quando a transmissão de informações ocorre por canais verbais e visuais, produziu-se um Objeto de Aprendizagem (OA) para o Ensino Médio e para a Educação Profissional, como método de ensino 
dinâmico e interativo no ensino-aprendizagem de Matemática, com atividades sequenciais, que utilizam interpretações gráficas para o ensino de Sistemas de Equações Lineares aplicado a circuitos de malhas.

Por se tratar de uma intervenção pedagógica diferenciada para o Ensino Médio e Educação Profissional, este trabalho foi aplicado na rede pública de ensino, as quais oferecem cursos ao nível médio e profissional. Conforme preconiza a Lei n. ${ }^{\circ}$ 9.394, de 20 de dezembro de 1996, Lei de Diretrizes e Bases - LDB em seu artigo primeiro:

A educação deve abranger os processos formativos que se desenvolvem na vida familiar, na convivência humana, no trabalho, nas instituições de ensino e pesquisa, nos movimentos sociais e organizações da sociedade civil e nas manifestações culturais (BRASIL, 1996, art. I.ํํ).

Dessa forma, a educação não pode se prender ao aspecto conteudista, que simplesmente prepara o aluno para outra etapa escolar, mas prepará-lo para a vida em comunidade, formando-o para ser um cidadão responsável e emancipando-o para o convívio social.

A LDB regulamenta a educação escolar oferecida predominantemente pelas instituições de ensino, estabelecendo que a mesma deverá vincular-se ao mundo do trabalho e à prática social. No artigo 2I tem-se que a educação escolar é composta pela educação básica, formada pela educação infantil, ensino fundamental e ensino médio; e educação superior. $\mathrm{O}$ artigo 22 traz que a finalidade da educação básica é "desenvolver o educando, assegurar-lhe a formação comum indispensável para o exercício da cidadania e fornecer-lhe meios para progredir no trabalho e em estudos posteriores".

No ensino médio, etapa em que, supostamente, os alunos possuem uma maior maturidade, fator conclusivo para prepará-los para a vida, a LDB, no artigo 35, define os objetivos gerais, os quais tratam da duração e finalidades desse período, conforme se verifica abaixo:

Art. 35 - O ensino médio, etapa final da educação básica, com duração mínima de três anos, terá como finalidades: I - a consolidação e o aprofundamento dos conhecimentos adquiridos no ensino fundamental, possibilitando o prosseguimento de estudos; II - a preparação básica para o trabalho e a cidadania do educando, para continuar aprendendo, de modo a ser capaz de se adaptar com flexibilidade a novas condições de ocupação ou aperfeiçoamento posteriores; III o aprimoramento do educando como pessoa humana, incluindo a formação ética e o desenvolvimento da autonomia intelectual e do pensamento crítico; IV - a compreensão dos fundamentos científico-tecnológicos dos processos produtivos, relacionando a teoria com a prática, no ensino de cada disciplina (BRASIL, 1996).

De tal modo, os objetivos definidos pelo artigo 35 contribuem para a prática docente, auxiliando o professor no desenvolvimento de seu trabalho, bem como norteando sua prática educacional com base legal para as formulações de suas atividades no processo ensino-aprendizagem.

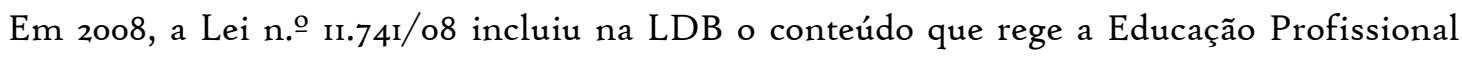
Técnica de Nível Médio e outras modalidades de ensino, oportunizando aos estudantes outras 
possibilidades de estudos e formação. Também a Lei n. 0 9.13I, de 24 de novembro de 1995, estabeleceu o Conselho Nacional de Educação, vinculado ao Ministério da Educação, cuja função é subsidiar, elaborar e acompanhar o Plano Nacional de Educação, manifestar-se sobre a modalidade de ensino e aperfeiçoar o sistema de ensino.

Em suas atribuiçães, o Conselho Nacional de Educação elaborou a Resolução n.. 2, de 20 de setembro de 2012, definindo as Diretrizes Curriculares Nacionais para o ensino médio, com a função de elaborar, planejar, implementar e avaliar as propostas curriculares das unidades escolares públicas e particulares, que oferecem o Ensino Médio. Esse mesmo Conselho definiu as Diretrizes Curriculares Nacionais para a Educação Profissional Técnica de Nível Médio, as quais devem ser desenvolvidas articuladamente ou subsequente ao ensino médio.

Portanto, o ensino profissionalizante deverá oferecer ao aluno a possibilidade de um exercício profissional, visto que o capacita para tal, habilitando-o para uma atividade técnica profissionalizante, que deve ser inserida com o ensino médio ou posterior a ele, sem prejuízo na formação da cidadania.

Os Parâmetros Curriculares Nacionais (PCNs) são referência básica para a elaboração das matrizes curriculares de cada escola e foram desenvolvidos para nortear os professores na elaboração dos conteúdos e ainda orientá-los na busca por novas abordagens e metodologias de ensino. Assim, é importante que, na elaboração das matrizes curriculares, os professores atentem para as competências e habilidades que o aluno pode adquirir nos conteúdos abordados. Da mesma forma, o PCNEM ressalta a importância da Matemática no relacionamento com a tecnologia e enfatiza que o pensamento matemático deve ser trabalhado ao longo de todo o ensino e, além do domínio do conteúdo, o aluno será levado a fazer matemática e pensá-la adequando-a ao uso da tecnologia.

Sabe-se que a Matemática é uma ciência aplicada em todas as disciplinas, e todas as áreas do ensino requerem alguma competência de matemática, o que põe em relevo a importância de se propor o objetivo desse conteúdo ao longo do ensino médio. Segundo o PCNEM de Matemática, os objetivos da Matemática no ensino médio, são:

- compreender os conceitos, procedimentos e estratégias matemáticas, que permitam desenvolver estudos posteriores e adquirir uma formação científica geral;

- aplicar os conhecimentos matemáticos a situações diversas, utilizando-os na interpretação da ciência, na atividade tecnológica e nas atividades cotidianas;

- analisar e valorizar informações provenientes de diferentes fontes, utilizando ferramentas matemáticas para formar uma opinião própria que lhe permita expressar-se criticamente sobre problemas da Matemática, das outras áreas do conhecimento e da atualidade;

- desenvolver as capacidades de raciocínio e resolução de problemas, de comunicação, bem como o espírito crítico e criativo;

- utilizar com confiança procedimentos de resolução de problemas para desenvolver a compreensão dos conceitos matemáticos; 
- expressar-se oral, escrita e graficamente em situações matemáticas e valorizar a precisão da linguagem e as demonstrações em Matemática;

- estabelecer conexões entre diferentes temas matemáticos e entre esses temas e o conhecimento de outras áreas do currículo;

- reconhecer representações equivalentes de um mesmo conceito, relacionando procedimentos associados às diferentes representações;

- promover a realização pessoal mediante o sentimento de segurança em relação às capacidades matemáticas, o desenvolvimento de atitudes de autonomia $e$ cooperação (BRASIL, 2000).

Dadas as orientações do PCNEM de Matemática para o ensino médio, buscando desenvolver um maior diálogo entre professores e gestores da educação, foi criado o documento intitulado “Orientações Educacionais Complementares aos Parâmetros Curriculares Nacionais” (PCN+), o qual complementa os PCNs. O mesmo ocorreu com o PCNEM, surgindo o PCNEM+, o qual apresenta um conjunto de sugestões, na prática educacional e sugestões curriculares relacionadas aos conteúdos em diferentes áreas do ensino. Conforme consta nas orientações do PCN+ de Matemática,

[...] a Matemática deve ser compreendida como uma parcela do conhecimento humano essencial para a formação de todos os jovens, que contribui para a construção de uma visão de mundo, para ler e interpretar a realidade e para desenvolver capacidades que deles serão exigidas ao longo da vida social e profissional (BRASIL, 2002, p. III).

Essa integração contribui para o relacionamento das disciplinas em diferentes áreas do conhecimento, propiciando uma investigação e compreensão de diferentes processos naturais. Nessa perspectiva, a presente pesquisa elaborou um Objeto de Aprendizagem, que auxilia os professores de Matemática no Ensino Médio e Educação profissional, com o objetivo de contribuir para a melhoria da qualidade do ensino, bem como proporcionar aos docentes materiais facilitadores no processo ensino-aprendizagem.

De acordo com Jucá (2006), devido à incompatibilidade de recursos físicos as universidades e centros de formação profissional utilizam-se de ambiente didático de simulação de componentes físicos, para sanar a falta do ambiente físico real. Em grande parte dos cursos profissionalizantes evidencia-se a necessidade de que os conteúdos específicos ensinados sejam relacionados à Matemática dentro de uma proposta menos tradicionalista. Para tanto, Segundo Lopes (2008), o professor deve ser criativo, de espírito transformador e buscar inovar sua prática pedagógica, dinamizando as atividades desenvolvidas em sala de aula, o que demanda o uso da tecnologia informática integrada ao ensino dos conteúdos.

Moran (2014) afirma que estamos caminhando para uma nova fase de convergência e integração das mídias. Conforme o autor, tudo começa a integrar-se e pode ser divulgado em alguma mídia e todos podem ser produtores e divulgadores de informações por meio dela. $\mathrm{O}$ mundo físico se reproduz em plataformas digitais e os serviços podem ser realizados tanto no meio físico quanto 
virtualmente. Há um diálogo crescente entre o mundo físico e o digital, em que as informações são compartilhadas nas atividades de pesquisa, lazer, relacionamento e outros, os quais têm impactando profundamente a educação escolar e as formas de ensino e aprendizado a que estamos habituados.

Moran (2014, p.30) é um defensor do uso da tecnologia no ensino. Para o autor, "a tecnologia digital móvel desafia as instituições a sair do ensino tradicional, em que o professor é o centro, para uma aprendizagem mais participativa e integrada”. Assim, na perspectiva de se criar um material didático, que auxilie o ensino de matemática, o 'OA' produzido é uma ferramenta salutar na prática pedagógica.

Ainda, segundo Moran (2014), as tecnologias oferecem dados, imagens e resultados de forma rápida e atraente, e o educador, como mediador do conhecimento, deverá ser capaz de orientar seus alunos na interpretação desses dados, contextualizando-os e relacionando-os, bem como motivando o educando a buscar sempre mais informações.

\section{Tecnologia em sala de aula}

Com a presença da tecnologia na sala de aula, Moran (2014) assevera que o ambiente tradicional será redefinido, passando a ser um local de começo e finalização de atividades de ensinoaprendizagem. O autor considera que a sala de aula deve ser um local de socialização, de organização

dos procedimentos didáticos, um ambiente motivador para que o aluno oriente as etapas de sua pesquisa e troca de experiências. De tal modo, a sala de aula perderá a característica de um espaço permanente de ensino, para se tornar um ambiente em que se inicia e se conclui o processo ensino-aprendizagem.

Todavia, Valente (1995) adverte que o sucesso da transmissão da informação e a realização das atividades não significa que de fato ocorrerá a compreensão e fixação do conteúdo. Conforme o autor, o uso da informática na educação, muitas vezes, segue o mesmo processo educacional tradicional de repasse do saber sem significado. Dependendo do tipo de software utilizado, do envolvimento do professor e da interação aluno-computador, o aluno pode ou não compreender aquilo que realizou.

Ainda, segundo Valente (1995), na mediação da construção do conhecimento do aluno, em interação com o computador, é importante que o docente compreenda a ideia do aluno, de modo que possa contribuir na formação do conhecimento deste. Portanto, o professor tem um papel fundamental na mediação da aquisição do conhecimento por meio dessa ferramenta. Para isso, é importante que estejam preparados para utilizá-la de forma que favoreça satisfatoriamente o processo ensino-aprendizagem. Nesse sentido, Behrens (2014, p. 77) corrobora que: 
Num mundo globalizado, que derrubas barreiras de tempo e espaço, o acesso à tecnologia exige atitude crítica e inovadora, possibilitando o relacionamento com a sociedade na totalidade. $O$ desafio passa por criar e permitir uma nova ação docente na qual professor e alunos participam de um processo conjunto para aprender criativamente, dinâmica, encorajadora e que tenha como essência o diálogo e a descoberta.

Moran, Masetto e Behrens (2014) comentam que trabalhar com tecnologia significa criar encontros mais motivadores e interessantes entre professores e alunos; não significa apenas trabalhar com técnicas de aulas expositivas que utilizam recursos tecnológicos como o datashow. Conforme Lévy (1996), defensor da mudança na prática pedagógica, a educação não pode estagnar em práticas arcaicas e ultrapassadas, as quais não refletem o momento da sociedade contemporânea. Nessa perspectiva, o ciberespaço $o^{2}$ pode oferecer múltiplas possibilidades para se trabalhar e aprimorar as capacidades cognitivas, propiciando aos alunos a formação de sua identidade, o desenvolvimento de sua capacidade crítica, de sua autoconfiança e de sua criatividade.

Há que se considerar que usar a tecnologia como suporte para a utilização da informática em sala de aula no ensino de Matemática não é uma tarefa simples. Contudo, é possível fazê-lo eficazmente e proveitosa, visto que a inovação e disponibilidade para aprender novas técnicas de ensino são papéis fundamentais na didática de uma aula que se deseja ativa e produtiva. Nesse sentido, Kensky (1998, p.6r) pondera que:

O estilo digital engendra, obrigatoriamente, não apenas uso dos novos equipamentos para a produção e apreensão do conhecimento, mas também novos comportamentos de aprendizagem, novas racionalidades, novos produtos e em novas áreas; obrigando-nos a não mais ignorar sua presença e importância.

Borba e Penteado (2012) asseveram que o uso da tecnologia no ensino pressupõe uma mudança, na prática docente, não sendo uma exigência somente daquelas pessoas que a utilizam, mas de todo o corpo docente. Devido à complexidade do ensino, às propostas didáticas envolvidas e às leis que estruturam o funcionamento da escola, o professor está sujeito a mudanças em sua forma de ensinar. Daí a emergência de se criar um ambiente tecnológico, que propicie melhor ensino-aprendizagem.

Apesar disso, não se pode desconsiderar o desafio de tal empreitada, tendo em vista que a metodologia educacional não acompanhou com a mesma rapidez os avanços tecnológicos. MORAN (200o, p. 23) pondera que "um dos grandes desafios para o educador é ajudar a tornar a informação significativa, a escolher as informações verdadeiramente importantes entre tantas possibilidades, a compreendê-las de forma cada vez mais abrangente e profunda e a torná-las parte do nosso

\footnotetext{
${ }^{2}$ É um ambiente virtual constituído por informações que circulam na rede de computadores e telecomunicação.
} 
referencial". Segundo o grupo de estudos Learning Objects Metadata - LOM (200o apud Wiley 200, p.5) estabelecido pelo Institute of Electrical and Electronics Engineers - IEEE,

[...] exemplos de tecnologia de suporte de aprendizagem incluem sistemas de treinamento baseado em computador, ambiente de aprendizagem interativos, sistemas de instrução inteligentes auxiliados por computadores, sistemas de ensino à distância e ambientes de aprendizagem colaborativa. Exemplos de Objetos de Aprendizagem incluem conteúdo multimídia, conteúdos educacionais, objetos de aprendizagem, software instrucional e ferramentas de software e pessoas, organizações ou eventos referenciados durante a aprendizagem tecnológica suportada.

Wiley (2000) considera que um Objeto de Aprendizagem é qualquer recurso digital que pode ser reutilizado para apoiar a aprendizagem. No que lhe concerne, Silva (20II), Munhoz (2013) e Braga (2014) definem o Objeto de Aprendizagem como um recurso digital que possui conteúdos educacionais, os quais são reutilizados em contextos diferentes.

Sendo o Objeto de Aprendizagem uma tecnologia recente, não existe um consenso universal a respeito de sua definição. Para Galafassi, Gluz e Galafassi (2013), um Objeto de Aprendizagem demanda características técnicas a serem aplicadas na educação. Dessa forma, os OAs podem ser analisados em duas perspectivas: pedagógica e técnica.

Galafassi, Gluz e Galafassi (2013) ponderam que alguns aspectos pedagógicos são importantes e devem ser considerados na elaboração de um OA, tais como:

interatividade: indica se há suporte às concretizações e ações mentais, requerendo que o estudante interaja com o conteúdo de alguma forma, podendo ver, ouvir ou responder algo;

autonomia: indica se os recursos de aprendizagem apoiam a iniciativa e tomada de decisão;

cooperação: indica se há suporte para os usuários trocarem ideias e trabalharem coletivamente sobre o conceito apresentado;

cognição: refere-se às sobrecargas cognitivas colocadas na memória do aprendiz durante o processo de ensino-aprendizagem;

fetividade: está relacionado com sentimentos e motivações do aluno com sua aprendizagem e com seus professores e colegas (GALAFASSI; GLUZ; GALAFASSI, 2013, p. 43).

Da mesma forma, as características técnicas são relevantes para uma melhor padronização dos OAs, pois facilita sua busca, classificação e armazenamento. Galafassi, Gluz e Galafassi (2013) apontam as características técnicas específicas dos OAs:

acesso: indica se um OA pode ser utilizado remotamente em muitos outros locais; agregação: indica se recursos podem ser agrupados em conjuntos maiores de conteúdos, incluindo estruturas tradicionais de cursos; autonomia: verifica se o objeto pode ser usado individualmente; classificação: permite a catalogação dos objetos auxiliando na identificação dos mesmos, facilitando o trabalho dos mecanismos de busca; formatos: refere-se aos formatos dos conteúdos digitais; durabilidade: indica se a contínua usabilidade de recursos educacionais se mantém quando a base tecnológica muda, sem reprojeto ou recodificação; 
interoperabilidade: verifica se é possível utilizar o OA em diferentes locais ou ambientes, independente de ferramentas ou plataformas;

reusabilidade: indica as possibilidades de incorporá-lo em múltiplas aplicações. (GALAFASSI; GLUZ; GALAFASSI, 2013, p. 43).

Portanto, considerando os aspectos pedagógicos e características técnicas dos OAs, buscouse embasamento teórico nas proposições de Jucá (2006), Moran (2014), Lévy (1996), entre outros autores, que discutem sobre o uso da tecnologia informática como meio de melhorar a prática pedagógica docente e de proporcionar um melhor ensino, aprendizagem ao educando. Nessa perspectiva, alabou-se um Objeto de Aprendizagem para o ensino médio e educação profissional Sistemas de Equações Algébricas Lineares aplicados em circuitos que se encontra disponível no site (http://www.fabioramos.mat.br/).

\section{Atividades do objeto de aprendizagem desenvolvido}

Ao desenvolver o objeto de aprendizagem, foram estabelecidas as metas propostas por Flanders (1995) de que o software de Matemática satisfaça os seguintes requisitos:

a) fazer da matemática uma ciência de laboratório, utilizar-se da tecnologia para a otimização do processo - com o computador, o tempo gasto para construir gráficos e equações é mais rápido e mais preciso;

b) eliminar a enfadonha monotonia dos cálculos rotineiros, fazendo com que o professor ganhe tempo ao ensinar as ideias matemáticas, aprofundando nos problemas propostos da álgebra;

c) ser usado como instrumento que testa, de maneira mais rápida e precisa, os cálculos e gráficos feitos manualmente.

Propõe-se, ainda, que o Objeto de Aprendizagem seja um produto educativo, que contribua nas concepções didáticas e pedagógicas e coopere, coletivamente, no relacionamento social entre o professor e aluno. Baseando-se nas ideias de Munhoz (2013, p.44):

Os OAs serão apresentados não apenas como elementos tecnológicos, mas como elementos desenvolvidos com finalidades didáticas e pedagógicas específicas, capazes de oferecer conteúdo de alta qualidade aos usuários, de forma flexível e com o uso de múltiplos meios.

O Objeto de Aprendizagem foi estruturado por uma sequência didática, utilizando-se da técnica de laboratório de informática para relacionar teoria e prática do conteúdo de sistemas de equações lineares, e também observados parâmetros definidores de Veiga (2008, p.136): “[...] teoria sem ser mera contemplação, mas guia da ação. A prática sem ser mera aplicação da teoria, mas a prática vista como a própria ação guiada e medida pela teoria”. 
O Objeto de Aprendizagem é composto de teoria, quadro de instrução, tela de manipulação e questionário de fixação do conhecimento. Em cada atividade, o usuário realiza uma leitura prévia do conteúdo a ser manipulado. Após essa leitura, é redirecionado a um link, no qual encontrará um quadro de instrução, por exemplo, (FIGURA I), a tela de manipulação (FIGURA 2), e o questionário (FIGURA 3).

Click na caixa do campo auxiliar para obter informações

Movimente os parâmetros $\left(E_{1}\right),\left(E_{2}\right),\left(E_{3}\right),\left(R_{1}\right),\left(R_{2}\right),\left(R_{3}\right)$ e $\left(R_{4}\right)$ e observe o circuito e o gráfico na tela

\section{Figura I - Quadro de instrução}

O quadro de instrução possui a finalidade de orientar o aluno na manipulação das atividades. É nele que se encontram as informações prévias para auxiliá-lo com as telas de manipulação mostradas na figura 2.

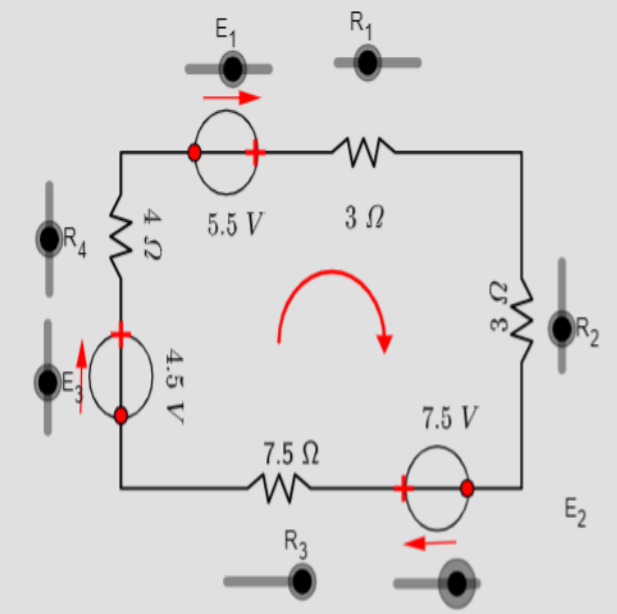

EXIBIR GRÁFICO $\checkmark$ EXIBIR TAXA DE VARIAÇÃO

$$
\begin{aligned}
& \qquad \frac{\Delta V}{\Delta \Omega}=\frac{8.75}{8.75}=1 \mathrm{~A} \\
& i=\frac{E_{1}+E_{2}+E_{3}}{R_{1}+R_{2}+R_{3}+R_{4}}=\frac{5.5+7.5+4.5}{3+3+7.5+4}=\frac{17.5}{17.5}=1 \mathrm{~A}
\end{aligned}
$$

Figura 2 - Tela de manipulação 
A tela de manipulação (FIGURA 2), desenvolvida no GeoGebra, concede a interatividade do usuário com o software, fixando e desenvolvendo os conceitos geométricos e algébricos necessários para responder aos questionários de fixação, mostrados na figura 3.

Questão 2

A taxa de variação com relação ao circuito e o gráfico representa
a) tensão
b) corrente
c) resistência
d) potência

Questão 3

Com a tensão fixada, movimente as resistências. Quanto maior a resistência,

a) maior a corrente e o gráfico se afasta da posição horizontal

b) menor a corrente e o gráfico se afasta da posição horizontal

c) maior a corrente e o gráfico se afasta da posição vertical

d) menor a corrente e o gráfico se afasta da posição vertical

\section{Figura 3 - Questionários de fixação}

O questionário de fixação é composto de questões de múltipla escolha, que direcionam o estudante à fixação e à aquisição de novos conceitos matemáticos. As questões possuem feedback, para que o usuário possa avaliar sua aprendizagem. Ao selecionar uma opção, aparece uma mensagem indicando o erro ou acerto, o que possibilita ao aluno rever os conceitos, caso necessário, e avaliar a aprendizagem gradativamente.

\section{Conclusão}

Para ilustrar esse cenário e potencializar a discussão acerca desse tema, verifica-se a necessidade de uma nova forma de ensinar, ou seja, um método de ensino que privilegie o dinamismo, propicie ao aluno prazer em aprender matemática e possibilite a construção de uma visão de mundo para ler e interpretar a realidade e para desenvolver capacidades que deles serão exigidas ao longo da vida social e profissional. É importante ressaltar que o interesse do aluno é essencial para que haja sucesso no processo ensino-aprendizagem, de nada servirá um material, que aos olhos do professor seja excelente, se o mesmo não despertar interesse no aluno. É preciso criar condições favoráveis para que o aluno se sinta atraído em aprender Matemática. 
Nessa perspectiva, o principal foco desta pesquisa é proporcionar ao aluno um ensino atrativo, aplicado e envolvente, motivando-o a solucionar problemas a partir de uma sequência didática.

Portanto, no Objeto de Aprendizagem proposto foi empregado o método de sequência didática, visando proporcionar ao estudante do Ensino Médio e Educação Profissional uma nova prática no aprendizado da Matemática, tornando-o sujeito do conhecimento, e os professores, no que lhe concerne, mediadores das discussões. À medida que avançarem nas atividades propostas, os estudantes conquistarão sua independência nos estudos, e os professores farão as intervenções necessárias no momento oportuno.

Como percurso metodológico, buscou a elaboração do Objeto de Aprendizagem para o ensino de sistemas de equações lineares explorar de forma dinâmica a geometria e a álgebra, para se obter a compreensão dos conteúdos propostos. Foram utilizadas as teorias disponíveis do produto educativo e conhecimentos prévios matemáticos adquiridos no decorrer da vida estudantil, aliados à prática da manipulação da ferramenta desenvolvida para tal ensino.

Considerando que as instituições de ensino, em sua grande maioria, oferecem um ensino descontextualizado, o qual ocorre, muitas vezes, de forma mecânica, sem oportunizar aos alunos uma interação entre o conhecimento adquirido e a prática cotidiana, espera-se que o OA produzido de fato contribua para o ensino e que também propicie ao professor de Matemática uma reflexão crítica, favorecendo uma mudança em sua prática pedagógica. Ainda, com o auxílio dessa tecnologia, espera-se que o professor possa desvincular o ensino da Matemática da aula estritamente expositiva, proporcionando uma prática pedagógica diferenciada, que desperte no aluno um maior interesse em aprender.

\section{REFERÊNCIAS}

ALMEIDA, Maria Elisabeth Bianconcini de. ProInfo: Informática e Formação de Professores. Vol. 2 Série de Estudos Educação a Distância Brasília: Ministério da Educação, Seed, 2000.

BRASIL. Lei no 9.394, de 20 de dezembro de 1996. Diretrizes e bases da educação nacional. Diário Oficinal da União, Brasília, 23 dez. 1996. Disponível em: 〈http://www.planalto.gov.br/ccivil_03/leis/L9394.htm〉. Acesso em: o8 mar. 2016.

\section{BRASIL. Ministério da Educação. Parâmetros Curriculares Nacionais para o Ensino Médio} (PCNEM). Brasília, 20oo. Disponível em: 〈http://portal.mec.gov.br/seb/arquivos/pdf/blegais.pdf〉. Acesso em: II mar. 2016. 
BRASIL. Ministério da Educação. Secretaria da Educação Média e Tecnológica. Orientações Educacionais Complementares aos Parâmetros Curriculares Nacionais PCN+: Ciências da Natureza, Matemática e suas Tecnologias. Brasília: MEC, 2002. Disponível em: $\langle$ http://portal.mec.gov.br/component/content/article?id=12598:publicacoes $\rangle$. Acesso em: o8 mar. 2016.

FLANDERS, Harley. Softwares para álgebra: o que devem ser? In: COXFORD, Arthur F.; SHULTE, Alberto P. (Org.). As ideias da álgebra. São Paulo: Atual, I995.

GALAFASSI, Fabiane Penteado; GLUZ, João Carlos; GALAFASSI, Cristiano. Análise Crítica das Pesquisas Recentes sobre as Tecnologias de Objeto de Aprendizagem e Ambientes Virtuais de Aprendizagem. Revista Brasileira de Informática na Educação RBIE, Porto Alegre, v. 21, n. 3, p. 4I-53, 2013.

JUCÁ, Sandro César Silveira. A relevância dos softwares educativos na educação profissional. Ciências \& Cognição, Rio de Janeiro, v. 8, p. 22-28, 2006.

KENSKY, Vani Moreira. Novas Tecnologias: o redimensionamento do espaço e do tempo e os impactos no trabalho docente. Revista Brasileira de Educação, Associação Nacional de Pós-graduação e Pesquisa em Educação, Rio de Janeiro, n. 7, jan./abr. 1998.

LÉVY, Pierre. O que é o virtual? São Paulo: Editora 34, 1996.

LOPES, Antônia Osima. Aula Expositiva: Superando o tradicional. In: VEIGA, Ilma Passos Alencastro (Org.). Técnicas de ensino: por que não? 19. ed. Campinas: Papirus, 2008.

MORAN, José Manoel. A Educação que desejamos: novos desafios e como chegar lá. 5. ed. Campinas: Papilus, 2014.

MORAN, José Manoel; MASETTO, T. Marcos; BEHRENS, Marilda Aparecida. Novas tecnologias e mediação pedagógica. 21. ed. Campinas: Papilus, 2014.

MUNHOZ, Antônio Siemsen. Objeto de Aprendizagem. Curitiba: Intersaberes, 2013.

VALENTE, José Armando. Informática na Educação: conformar ou transformar a escola. Perspectiva, Florianópolis, n. 24, ano I3, p. 41-49, jul./dez. 1995.

WILEY, D. Connecting Learning Objects to Instructional Design Theory: A definition, a metaphor and a Taxonomy. [S.l.: s.n.], 2000. Disponível em: $\langle$ http://reusability.org/read/chapters/wiley.doc〉. Acesso em: I9 jan. 2015. 